Zoology Department

Faculty of Science AL Azhar University (Assiut Branch).

\title{
COMPARATIVE STUDIES OF LINGUAL PAPILLAE IN FOUR RODENTS SPECIES IN EGYPT BY LIGHT AND SCANNING ELECTRON MICROSCOPY
}

(With 15 Figures)

\section{By \\ M.A. MOUSTAFA \\ (Received at 22/3/2006)}

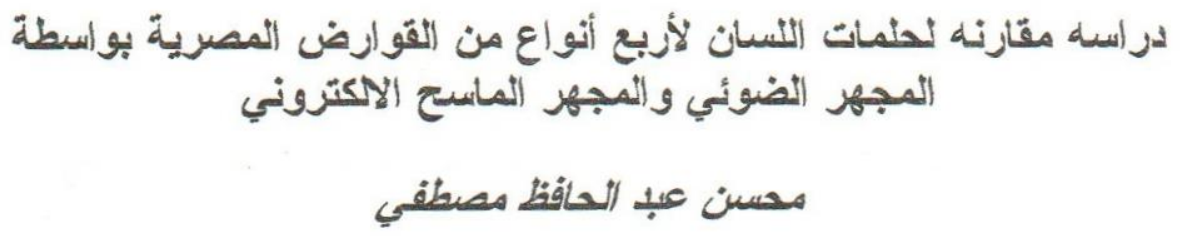

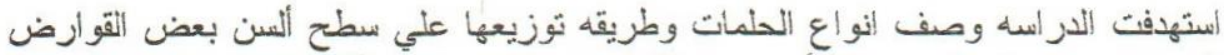

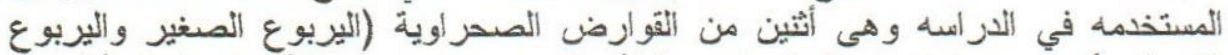

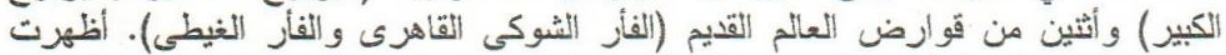

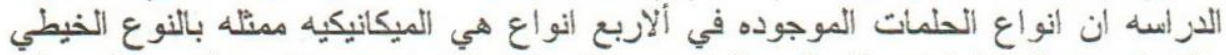

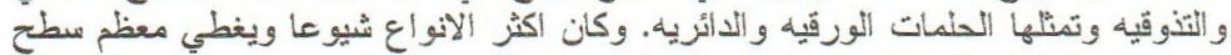

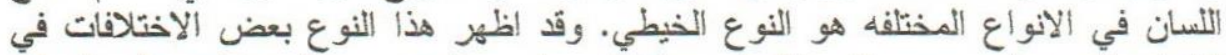

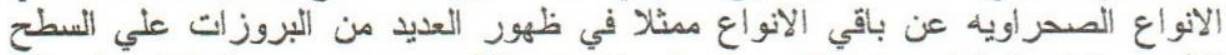

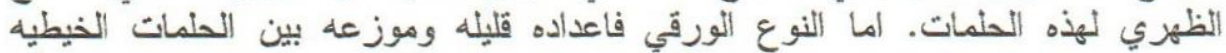

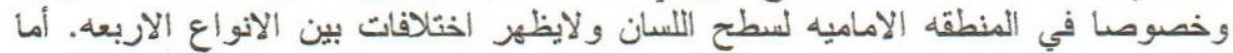

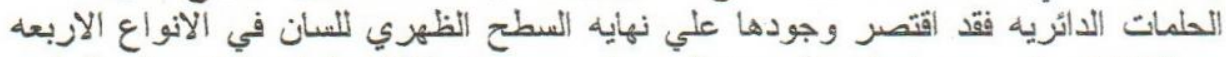

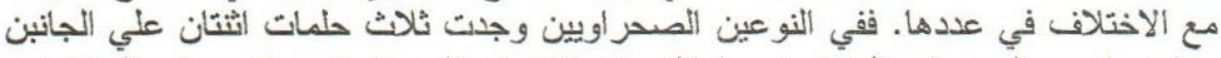

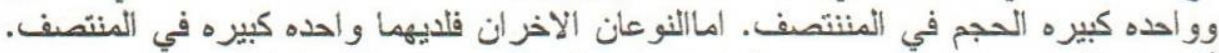

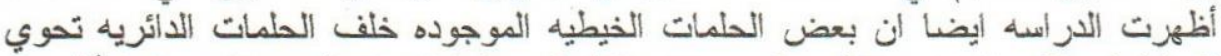

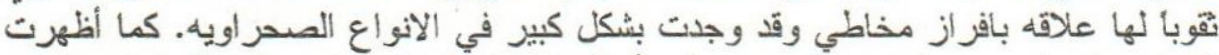

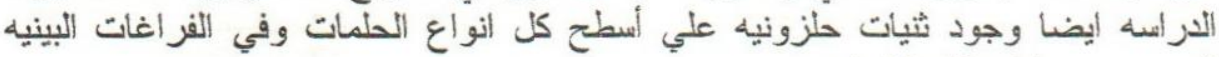

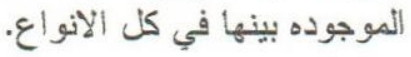

\section{SUMMARY}

The present study examined the distribution patterns and types of lingual papillae for four rodent species, desert rodents Jaculus jaculus \& Jaculus orientalis and old World mice \& rat Acomys cahirinus and 
Arvicanthis niloticus by light and scanning electron microscopy. Filliform (mechanical papillae), fungiform and circumvallate papillae (gustatory papillae) were found in the four species. Both Acomys and Arvicanthis species have widespread conical and slightly branched filfiorm papillae, while the two Jaculus species have widespread highly branched filiform papillae. In all species, fungiform papillae are abundant in the tip of the tongue and scattered among filliform papillae on the dorsal surface. Both species of Acomys and Arvicanthis have a single ciricumivallate papilla, while the two jaculus species have three circumivallate papillae at the posterior area of the lingual prominence. On the postrior third of both Jaculus species tongue, pores related to the secretion of mucus were frequently scattered next the circumivallate papillae. Microridges are visible at high magnification in all types of papillae as well as in interpapillar zone of all species.

Key words: Lingual papillae, light microscopy, scanning electron microscopy, Dipodidae, Muridae.

\section{INTRODUCTION}

Recently light and scanning electron microscopy studies of mammilian tongue have been performed by Kumar et al. (1998) and Kumar and Bate (2004), Emura et al. (1999, 2000, 2002 a \& b, 2004) Martinez et al. (2000) Abd-Elnaeim et al. (2002) Yoshimura et al. (2002), Jackowiak and Godynicki (2004), Kobayashi et al. $(2003,2005)$ and Okada and Schraufngel (2005). The dorsal surface of the tongue consists of epithelial tissue projections are known as tongue papillae (Martini et al., 2000). The mammalian tongue is covered with four kinds of papillae fungiform, circumvallate, foliate and filiform papillae. These papillae are distributed in specific pattern (Iwasaki et al., 1999). Filiform papillae are distributed over the entire dorsal surface of the tongue and aid in the movement of food about mouth (Ojima et al., 1996). However, Fungiform, circumvallate, and foliate papillae are known as the gustatory papillae which contain taste buds and work as sensory organs (Mbiene et al.,1997).

The morphological and histological features of mammalian tongues reflect the differences among the life styles of mammals (Iwasaki 2002).

It is therefore of interest to investigate the morphology of the lingual papillae of Egyptian desert rodents in comparison with Cairo and 
Nile valley rodents by using light and scanning electron microscope. Two rodent species; lesser Egyptian jerboa Jaculus jaculus \& greater Egyptian jerboa Jaculus orientals (Family: Dipodidae) In addition to Cairo spiny mouse Acomys cahirinus \& Filed rat Arvicanthis niloticus (Family: Muridae) were used in this work. The spiny mouse has adapted to live in the midst of human habitation, even in the center of Cairo, while Nile rat is a common inhabitant and serious agriculture pest in Delta and Nile Valley (Hoath, 2003).

\section{MATERIALS and METHODS}

Four adult rodent species, lesser Egyptian jerboa Jaculus jaculus (4 males and 4 females) \& greater Egyptian jerboa Jaculus Orientals ( 3 males and 3 females), Cairo spiny mouse Acomys cahirinus (2males and 2 females) and Nile rat Arvicanthis niloticus (1male and 1 female) were used in this study. Tongues were excised ,fixed,and prepared for examination of lingual papillae by light and scanning electron microscopy.

\section{Scanning electron microscopy:}

Tongues were taken from species fixed in $2.5 \%$ glutaraldehyde dehydrated, dried, coated and examined in Assiut scanning electron microscope (JEOL) JSM-5400 LV.

\section{Light microscopy:}

For light microscopy, the tongues were fixed in $10 \%$ formalin .After dehydration in graded ethanol the tongues were embedded in paraffin and cut in serial sections ( $5 \mu \mathrm{m}$ thickness). For each specimens, sections were stained with hematoxyline-eosin.

\section{RESULTS}

Lingual papillae of old World rodents Acomys cahirinus and Arvicanthis niloticus:

In both species lingual papillae cover the dorsum of the tongue and continue onto the sides. Three types of lingual papillae were observed on the lingual mucosa: filiform, fungiform and circumvallate .The most widespread of these structures are filiform papillae (mechanical type) (Fig.1).

In spiny mouse Acoyms cahirinus scanning electron microscopy revealed that filiform papillae are compactly distributed over entire dorsal surface of the tongue until just anterior tip. Most filiform papillae 
are oriented posteriorly, except for the vicinity of the anterior tip where they oriented anterirorly (Figs. 1 and 2 A \& B). They are simple (conical) or branched in the extremity. Conical ones have a wide base and narrowed to a thin apex (Figs. $3 \mathrm{~A}, \mathrm{~B} \& \mathrm{C}$ ). They are distributed on the anterior half of the dorsal tongue surface. Large branched ones with a basally convex central area, are branched into two pointed projections (Figs. 3A\&D). These large papillae are distributed in the median-dorsal eminence (prominent median-dorsal elevation with $U$ shaped basal groove) (Fig. 3A). On the posterior third of the tongue next the branched filliform papillae, conical type of filform papillae are extended to the posterior until circumvallate papiillae (Fig. 4).

Also, both species present two of gustative papillae types (fungiform and circumvallate). A relatively small number of fungiform papillae are scattered among the filiform papillae (Fig. $3 \mathrm{~B}$ and $5 \mathrm{~A}$ ). Some of them have no taste buds on the dorsal surfaces (Fig. 5 B). In the middle of the posterior end of the lingual body, a single circumvallate papilla was observed in both species. It is large-sized, elliptical, with a convex surface and is surrounded by groove and crescent shape pad (Fig. 4). Many taste buds are present on the papillary lateral surface as well as in the papillary groove (Fig. 6). Typically serous-appearing gland (Von Ebner's gland) is located beneath circumvallate papilla. Ducts extended toward the circumvallate papilla opening into the trough and around it (Fig. 6).

\section{Lingual papillae of desert rodents Jaculus species:}

Like old World rodent species, filiform papillae cover the dorsum of the tongue and continue onto the sides. However, the structure of filiform papillae on the Jaculus tongue (both species) differs from that in Acoyms cahirinus and Arvicanthis niloticus. Branched filiform papillae which have three to five projections cover the anterior tip of the tongue and extend some distance to the ventral surface (Figs.7\& 8\& 9A). Projections of most filiform papillae are oriented posteriorly, while those cover the antereior tip and narrow area of ventral surface of Jaculus tongue are oriented anteriorly (Fig. 8). In the middle third (median-dorsal eminence) of the tongue, filiform papillae have five to eight projections. These large papillae are crown-shaped, with a basally concave central area, surrounded by pointed projections (Fig. 9B). In the posterior third, they decrease in number of branches (Fig. 9C).

Like all species in the present study Fungiform papillae have a thick dome-like structure with taste bud on the top of some of them. 

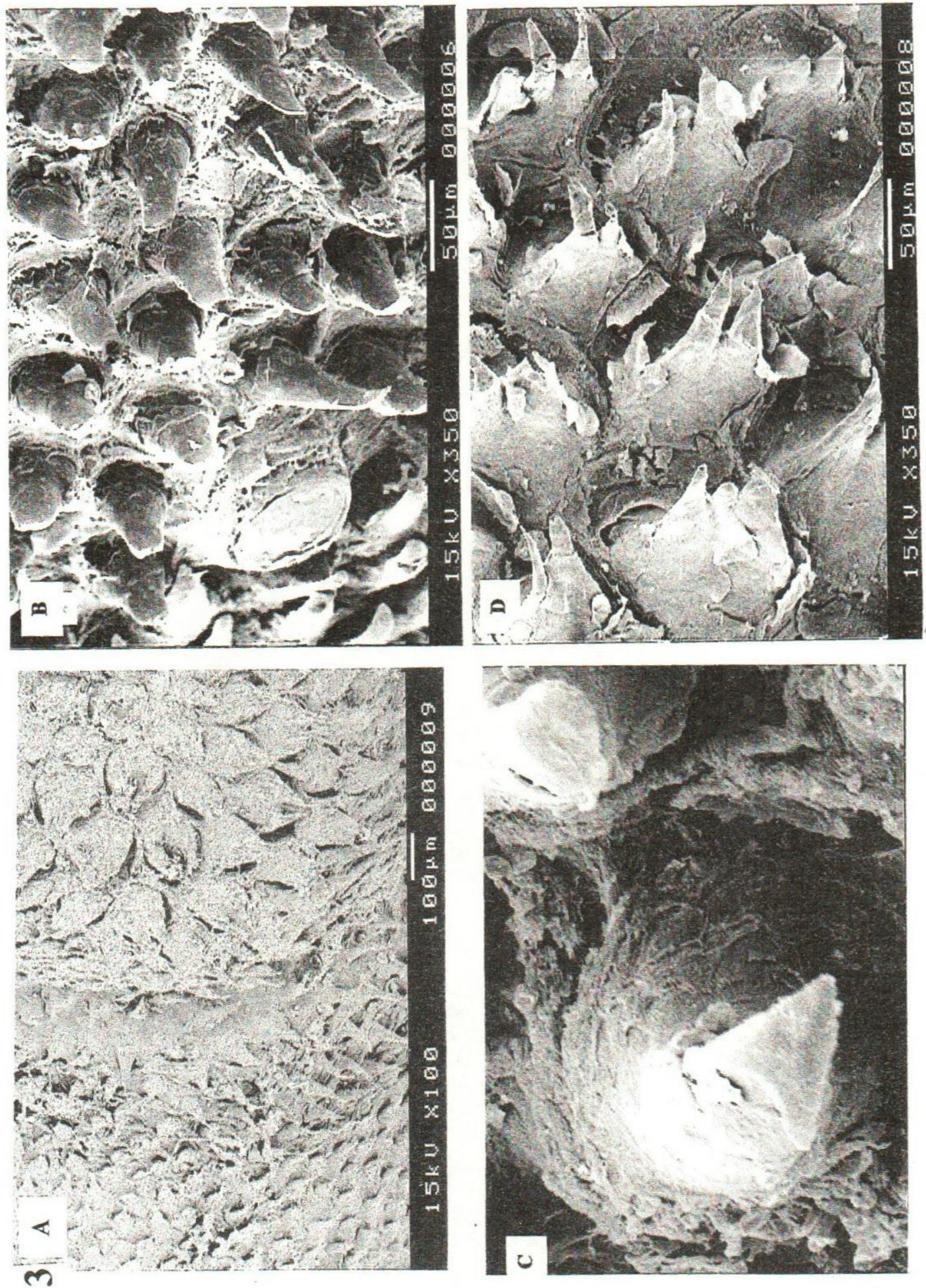
Assuit Vet. Med. J. Vol. 52 No. 109 April 2006

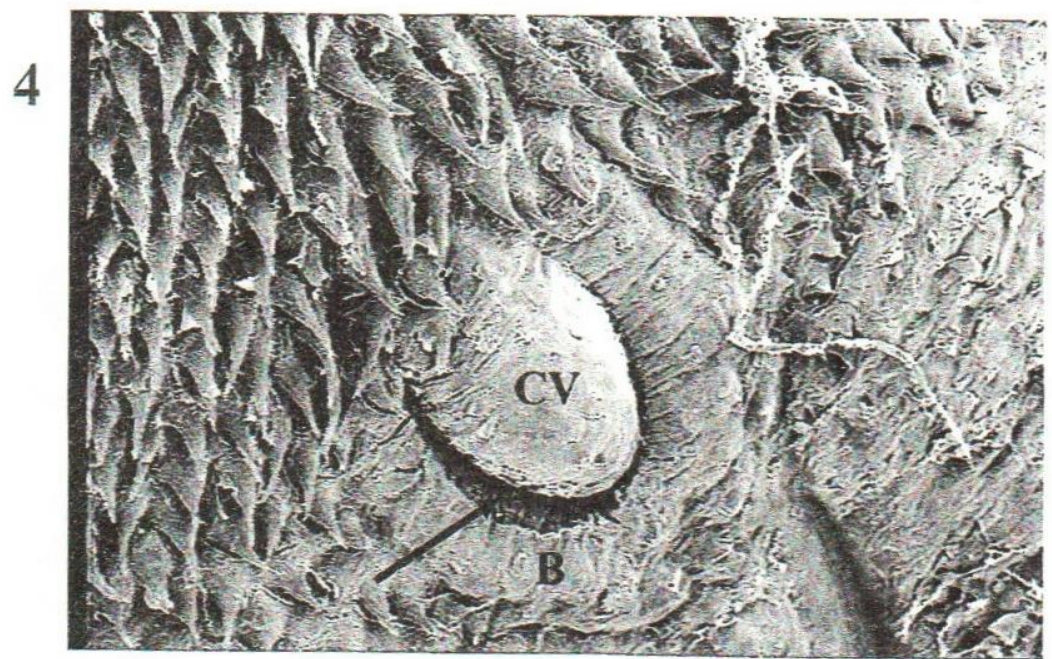

5

A

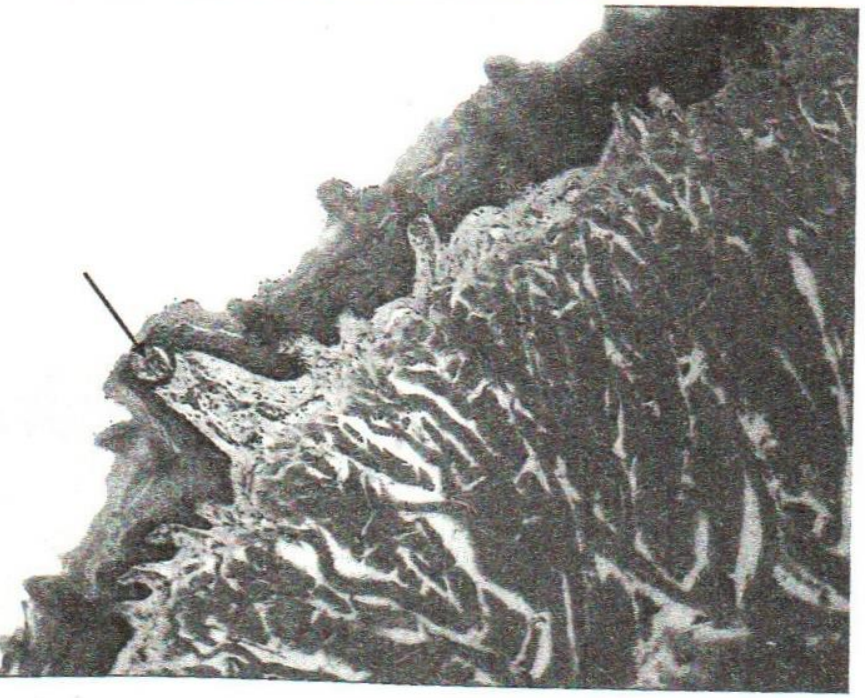

B
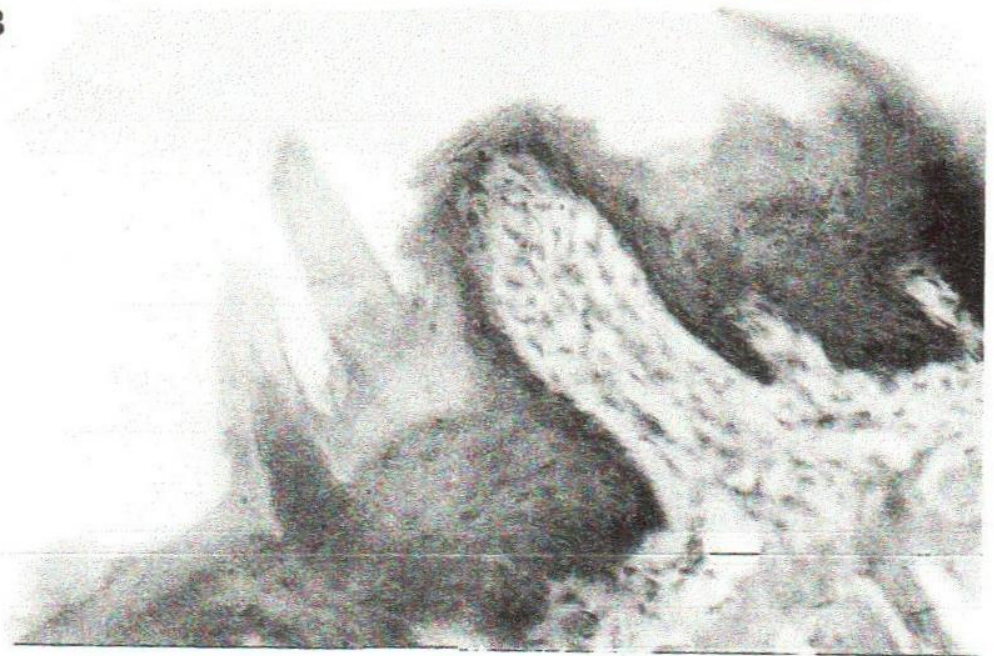


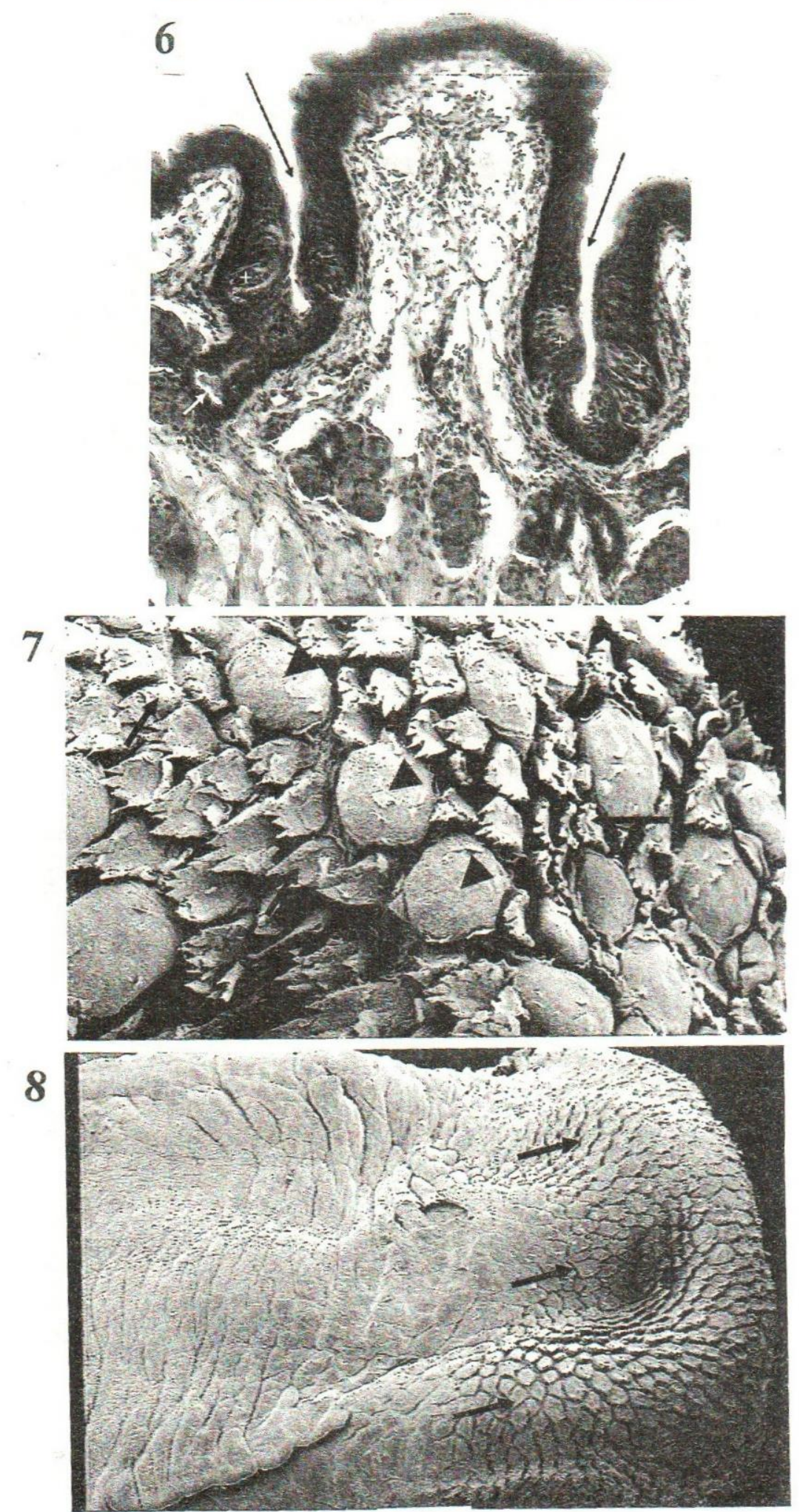


Assuit Vet. Med. J. Vol. 52 No. 109 April 2006
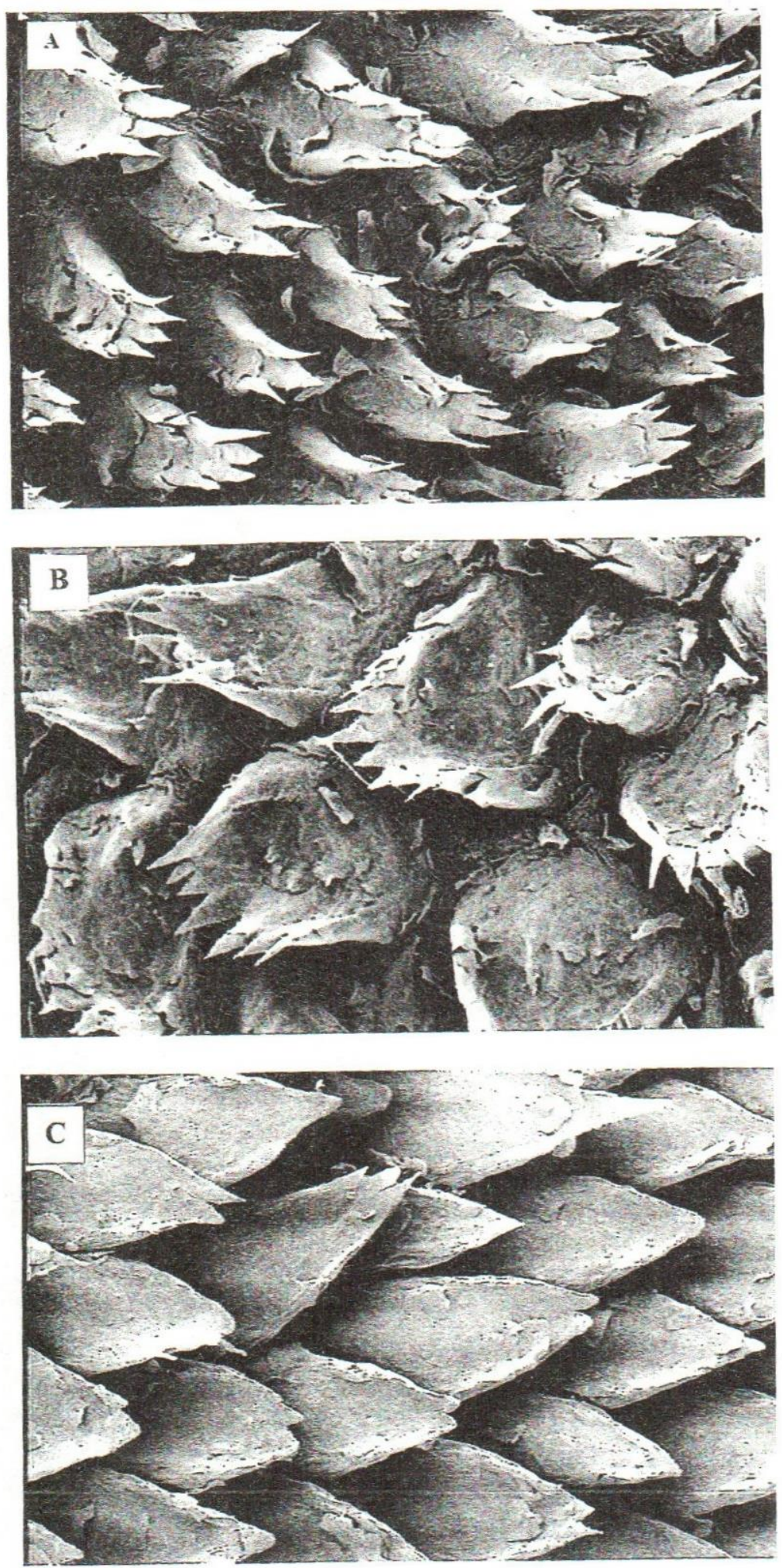

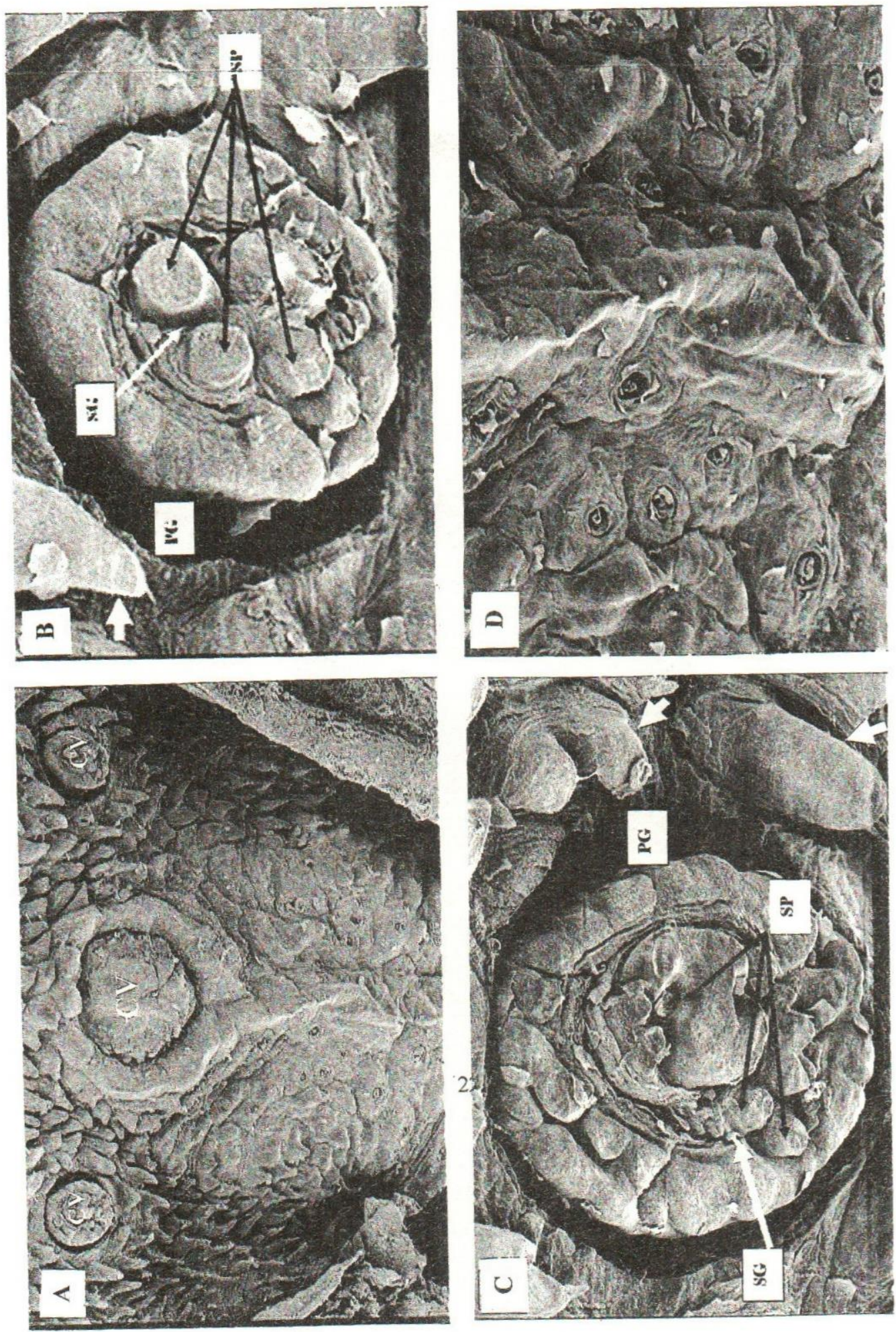

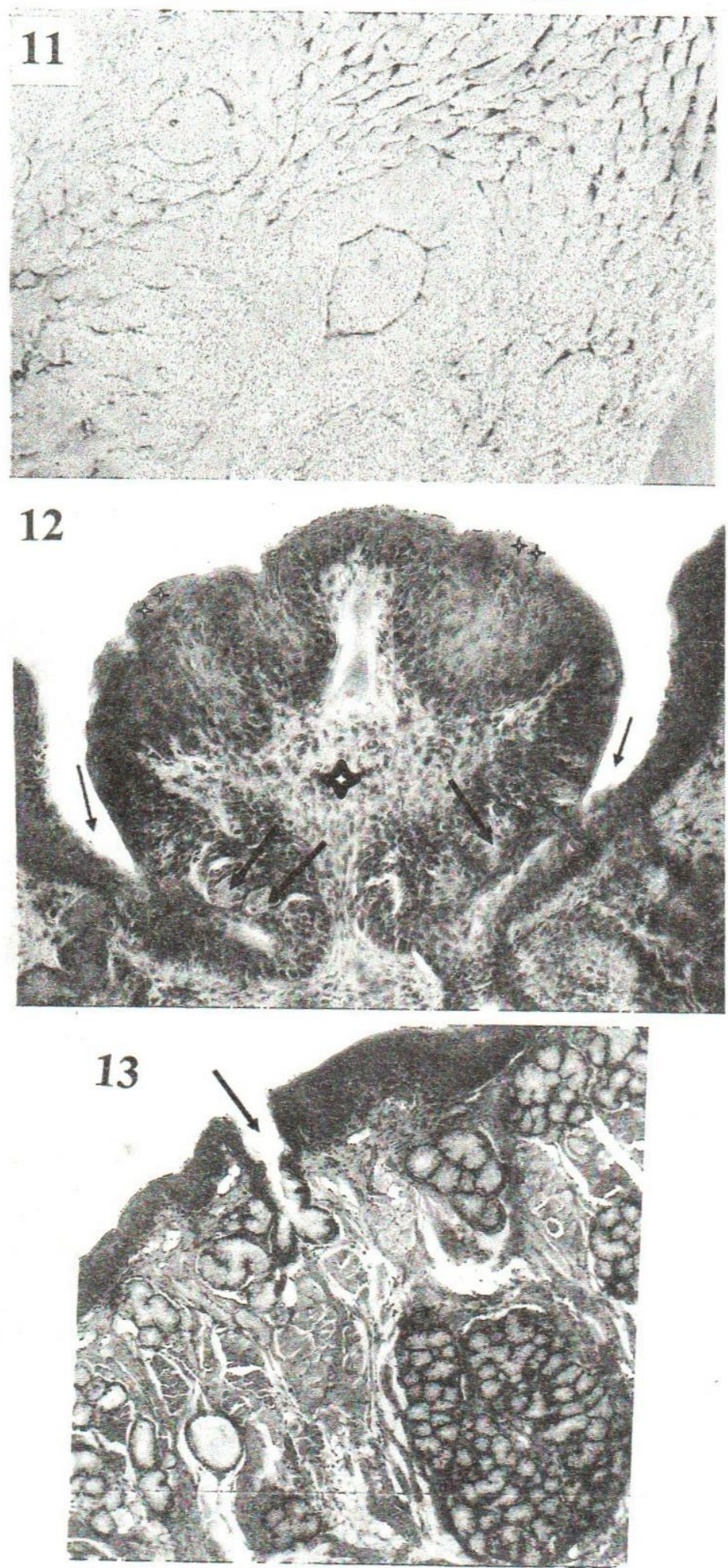

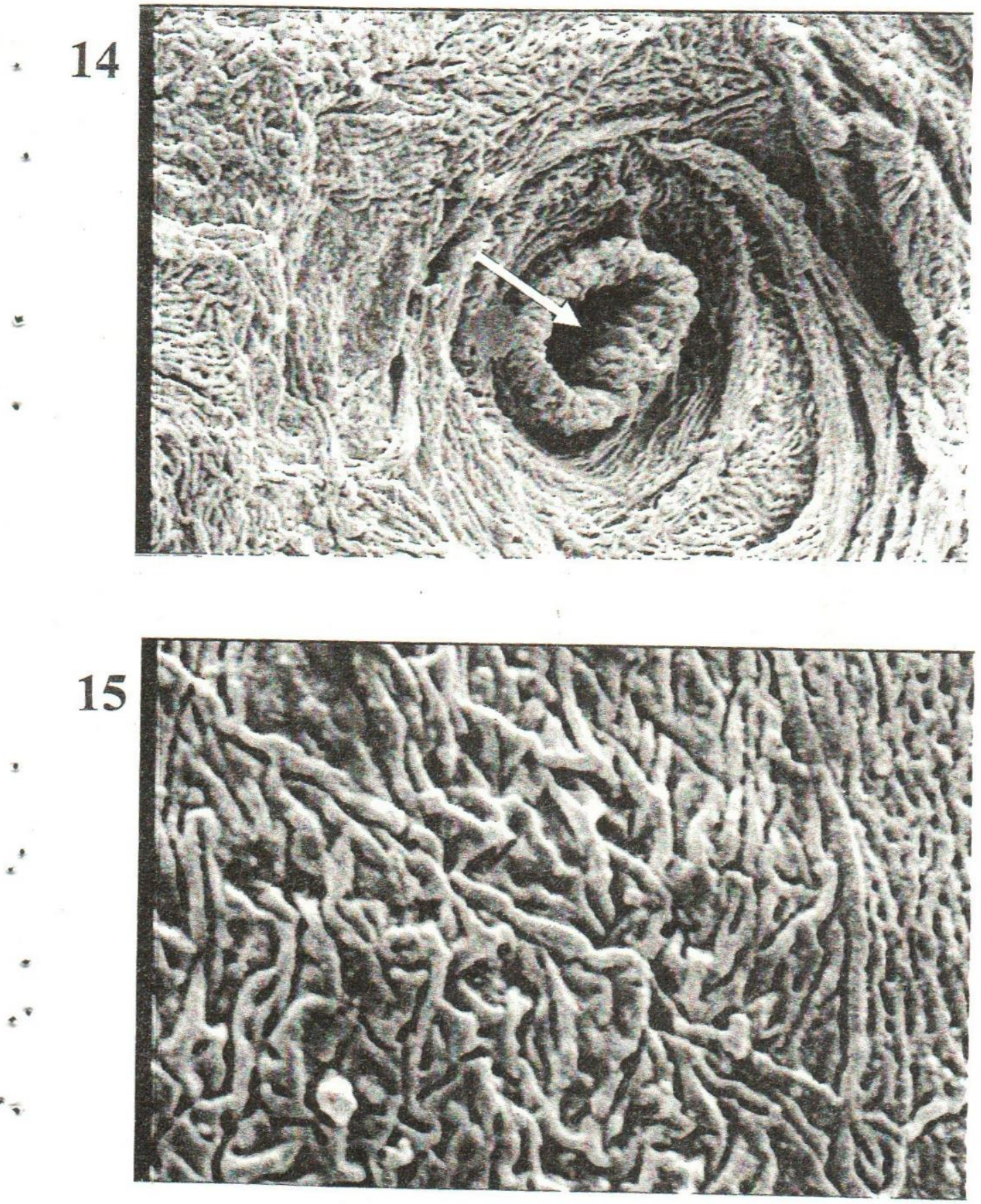


\section{LEGENDS OF FIGURES}

Fig. 1: Magnification view of the anterior dorsal surface of the lingual body in a spiny mouse Acomys cahirinus. Conical filiform papillae are widely distributed and their prjections are oriented posteriorly. Dome-shaped fungiform papillae (white arrows), which are low and wide, are scattered among filiform papillae. X100

Fig. 2: A- lower magnification view of the anterior ventral surface of the lingual body in a spiny mouse Acomys cahirinus. Note papillae are restricted just on the tip (arrows).X35 B- Higher magnification of the previous image on the anterior tip. Note the projections of filiform papillae decline anteriroly and the presence of fungiform papillae (arrows).X100

Fig. 3: A. Magnification view of dorsal surface of the lingual body in a spiny mouse Acomys cahirinus. Note the anterior region with conical-shaped filiform papillae and median-dorsal eminence region with large branched filform papillae.X100 (B) Higher magnification of anterior region .Note conical fiform papillae and fungiform papilla. X350. (C) Higher magnification of conical filiform papilla. Note its projection is oriented posteriorly. X1.500 (D) Higher magnification of large branched filiform papillae. Note base convex of central area of papillae with two pointed projections. X350

Fig. 4: Magnification view of circumivallate papilla (CV) of Acomys cahirinus and conical filiform papillae existe around it. Note crescent -shaped pad (B) and deep papillary groove (arrow).X100

Fig. 5: A-B Light micrograph of sagittal section of Acomys cahirinus fungiform papillae. A- Note one fungiform papilla has taste bud (arrow) in the dorsal surface H\&E.X200 (B) while the other without it .H\&E.X400

Fig. 6: Light micrograph of a transverse section of Acomys cahirinus circumivallate papilla. The light spherical areas in the epithelium of the walls of the papilla (white stars) are taste buds. A duct (white arrow) from the underlying gland of von Ebner can be seen opening into the trough space (black arrows) around the papillae H\&E.X1000.

Fig. 7: Magnification view of the anterior dorsal surface of the lingual body in a greater Egyptian jerboa Jaculus orientals, branched filiform papillae (thin arrows) are widely distributed and their prjections are oriented posteriorly. Dome-shaped fungiform 
papillae (thick arrowheads), which are low and wide, are scattered among filiform papillae. X150

Fig. 8: A lower magnification view of the anterior ventral surface of the lingual body in a Jaculus orientals. Note papillae are extended from the tip to some distance ventrally (arrows) and their projections decline anteriorly. X35

Figs. 9: A\&B\&C Higher magnification of 3 types of filiform papillae on dorsal surface of the lingual body in a Jaculus orientals. Note (A) branched type with 3-5 projections in the anterior region (B) branched type with $5-8$ projections in the median-dorsal eminence and (C) slightly branched (approximately conical) in posterior region. X200

Fig. 10: lower magnification of female Jaculus orientals circumivallate papillae A-Dorsal view showing 3 papillae (one central and two lateral). Note papillary grooves and oval pad around the central one. X35 (B-C) Higher magnification of right and left papillae showing the secondary papillae (sp), secondary grooves (sg) and primary papillary grooves $(\mathrm{pg})$, the circumivallate papillae are surrounded by filiform papillae(fi). X200(D)-Higher magnification of the previous image next the circumivallate papillae. Note pores and small filiform papillae with large base and the tip without projections. X100

Fig. 11: lower magnification of three circumivallate papillae of female Jaculus jaculus. Note small circumivallate papillae without secondary papillae and intermediate grooves. X50

Fig. 12: Light micrograph of tongue mucosa of female Jaculus orientals showing large circumivallate papillae. Note, epithelial layer(**), lamina propria $\left({ }^{*}\right)$, taste buds (thick arrows) and primary groove (thin arrows). H\&E.X1000

Fig. 13: Light micrograph of sagittal section of the dorsal tongue surface on the posterior third next the circumivallate papillae of female Jaculus orientals. Note one pore contact between mucus gland and dorsal surface via duct (arrow). H\&E.X400

Fig. 14: Scanning electron microscope of the dorsal tongue surface on the posterior third next the circumivallate papillae of female Jaculus orientals. Note one pore (arrow) and microridges .X3.500

Fig. 15: Higher magnification of microridges on the body of filiform papilla. X7.500 


\section{DISCUSSION}

Morphology of the dorsal surface of the present study species tongues is unknown and has not been described previously.However,the present study of the rodent tongues (desert and old world rat and mice), like in other mammals (Ojima et al,1996), verified that filiform papillae are the main mechanical papillae. Since the absence of taste bud allows to establish that they have only mechanical function. The shape and the size of the filiform papillae presented some regional differences in the tongue of desert and old World rodents. According to Iwasaki et al (1987a), the reason for the distribution of different types of filiform papillae in different areas of the tongue is thought to be based on their functional differences. Thus, the anterior part of the tongue may possibly contribute to the touch and prehension of the food, while the posterior part may facilitate the swallowing of the masticated food. Since these tongues represent two different habitats, the variation in size and shape of filiform papillae between old World and desert rodent may reflect form of adaptation to the environment. This suggestion was accepted, since jaculus species has a high habitat tolerance and regarded by Harrison and Bates (1991) as one of the most successful mammalian colonists of the desert. So, as in other species (Paz Cabello et al., 1988), the wide distribution and high number of branched filiform papillae in both jaculus species may be suggested a highly protective role of the lingual surface.

In all species studied here, some fungiform papillae have taste buds in the epithelium of the dorsal aspect of them. On the other hand, various authors have suggested that fungiform papillae without taste bud may not exist (Farbaman,1980, Robinson1989 and Robinson and Winkles 1990). Robinson and Winkles (1990) have discussed that the observations of fungiform papillae without taste bud are probably due to the method used in these studies. Furthermore, they have concluded that the series of sections should be cut parallel to the dorsal. In all species studied here, no taste bud was observed in all serial sections of many fungiform papillae. The desert and old World rodents, therefore, appear to have fungiform papillae of a strictly mechanical type.

The posterior third of the dorsum tongue of Acomys cahirinus and Arvicanthis niloticus presented a single circumivallate papilla. Similar number of this papilla was also observed in three geomyids and 12 heteromyid rodent species (Frederick et al.,1994) Wistar rat (Sbarbati et al., 2002), mouse (Iwasaki et al.,1996). In contrast to the most rodent 
species, three circumivallate papillae were observed in Jaculus species. This quantity also observed in rodent Manchurian chipmunk (Kobayashi et al., 1992), in opossum (Okada and Schraufnagel, 2005) in Koala, (Kobayashi et al,. 2003) in Japanese Macaque and Savanna monkey (Emura et al., 2002a) and in large flying fox (Emura et al., 2002b). However, other mammals like goat and cattle had 15 or more papillae (Kobayashi et al., 2005). The reason of this variation among mammalian species is not clear until now.

On the posterior third of the tongue next the circumvallate papillae, small filiform papillae with large base and the tip without projections were observed The surface of these papillae has many pores and microridges. These pores are numerous and clearly observed by scanning electron microscope in jaculus species. Similar findings were observed in other animals as monkey (Iwasaki et al., 1988) bat (Pastor et al.,1993). The previous authors reported that, these pores may serve for the production of mucous over the papillary surface.This sugesstion was confirmed by light microscope in the present study. The numerous appearance of these pores in jaculus species may be to keep their tongues in moist condition since the desert more arid and of higher ambient temperature.

Microridges observed in the filiform, fungiform and circumivallate and interpapillar surface are similar to those reported in other mammals as mouse (Utiyama et al., 1995), monkey (Iwasaky et al., 1992), opossum (Martinez et al., 1998), wild boar and pig (Chamorro et al., 1994), Chinchilla (Martinez et al., 2000) and cow and horse (Chamorro et al., 1986). They are an adaptive structure involved in the holding and spreading of mucous (Sperry and Wassersug.,1976), which protect the superficial cells of the oral epithelium (Nair and Schroeder, 1981). As was suggested by Iwasaky et al. (1987a) for other mammals, filiform papillae and microridges may also function as a supporting structure for food-uptake, mastication and swallowing.

The present study indicates that the principle role of mammalian (rodent) tongue is to facilitate eating. The morphological characteristics of the tongue of the two jaculus species appear to have been transformed to adapt to a desert environment, however they possess some structure similar to old World rodent. But one question remain to be answered concerning the significance of variation number of circumvallate papillae among mammalian species. 


\section{REFERENCES}

Abd-Elnaeim, M.; Zayed, E. and Leiser, R. (2002): Morphology characteristics of the tongue and its papillae in the donkey (Equus asinus): a light and scanning electron microscopical study. Annals of Anatomy.184: 473-480

Chamorro, C.; De Paz, P. and Fernandez, J. (1986): Comparative Scanning electron microscopic study of the lingual in two species of domestic mammals (Equus caballus and Bos taurus). Acta Anat. 125: 83-7.

Chamorro, C.; Fernandez, J.; De Paz, P.; Pelaez, B. and Anel, L. (1994): Scanning electron microscopy of the boar and pig lingual papillae. Histol. Histopathol. 9: 657-67.

Emura, S.; Hahakawa, D.; Chen, H. and Shoumura, S. (2002a): Morphology of the dorsal lingual papillae in the Japanese macaque and Savana monkey. Anat Histol Embryol 31(5) 313316.

Emura, S.; Hahakawa, D.; Chen, H. and Shoumura, S. (2004): Morphology of the lingual papillae in the tiger. Okajimas folia Ant Jpn. 81(2-3): 39-43.

Emura, S.; Hahakawa, D.; Chen, H.; Shoumura, S.; Atoji, Y. and Wijayanto, H. (2002b): SEM study on the dorsal lingual surface of the large flying fox, Pteropus vampyrus. Okajimas folia Ant Jpn. 79 (4): $113-9$.

Emura, S.; Tamada, A.; Hahakawa, D.; Chen, H.; Jamali, M.; Ozawa,

$Y$. and Shoumura, S. (1999): SEM study on the dorsal lingual surface of Microtus montebelli. Okajimas folia Ant Jpn. 76(4): 171-7.

Emura, S.; Tamada, A.; Hahakawa, D.; Chen, H. and Shoumura, S. (2000): Morphology of the dorsal lingual papillae in bush dog (Speothos venaticus). Okajimas folia Ant Jpn. 77(5): 137-41.

Farbaman, A.L. (1980): Renewal of taste bud cell in rat circumvallate papillae. Cell Tissue Kinet.,13.349-357.

Frederick, B.; Stangl, J.R. and Russell, S. Pfau (1994): Gross morphology and distribution patterens of lingual papillae in some Geomyid and Heteromyid Rodents. Proc Okla. Acad. Sci. 74.25-39.

Harrison, D.L. and Bates, P. (1991): The mammals of Arabia.

Sevenoaks: Harrison Zoological Museum.

Hoath, R. (2003): A field guide to the mammals of Egypt. The American University in Cairo press Cairo- New York 190-204. 
Iwasaki, S. (2002): Evolution of the structure and function of the vertebrate tongue. J. Anat. 201 1-13.

Iwasaki, S.; Miyata, K. and Kobayashi, K. (1987a): Comparative studies of the dorsal surface tongue in three mammalian species by scanning electron microscopy. Acta. Anat. 128: 140-6.

Iwasaki, S.; Miyata, K. and Kobayashi, K. (1988): Scanning -electronmicroscopic study of the dorsal lingual surface of the Squirrel monkey. Acta Anat (Basel) 132(3): 225-9.

Iwasaki, S.; Yoshizawa, H. and Kawaharal (1996): Study by scanning electron microscopy of the morphogenesis of three types of lingual papilla in the mouse.Acta Anat (Basel) 157(1): 41-52.

Iwasaki, S.; Yoshizawa, H. and Kawahara, I. (1999): Ultrastructural study realtionship between the morphogenesis of filiform papillae and the keratinization of the lingual epithelium in the rat. J. Ant, 195 (pt 1). 27-38.

Iwasaki, S.; Yoshizawa, H. and Suzuki, K. (1992): Fine structure of the dorsal lingual epithelium of the Japanese monkey Macaca fuscata fuscata. Acta Anat., 144 267-77.

Jackowiak, H. and Godynicki, S. (2004): The scanning electron microsopic study of lingual papillae in the silver fox (Vulpes vulpes fulva, Desmarest,1820) Ann Anat. 186: 179-83.

Kobayashi, K.; Kumakura, M.; Yoshimura, K.; Nonaka, K.; Murayama, T. and Hennebrg, M. (2003): Comparative morphological study of the lingual papillae and their connective tissue cores of the koala. Anat Embryol (Berl) 206(4): 247-254.

Kobayashi, K.; Jackowiak, H.; Frackowiak, H.; Yoshimura Kumakura, M.K.; Nonaka, K. and Murayama Kobayashi, K. (2005): Comparative morphological study on the tongue and lingual papillae of horses (Perissodactyla)and selected ruminantia (Artiodactyla). Ital J. Anat Embryol 110 (2 suppl 1): 55-63.

Kobayashi, S.; Toh, H.; Tomo, S.; Ideguchi, T.; Nagamoto, S.; Kikuchi $N$. and Itoh, $R$. (1992): Scanning electron microscopic study on the lingual papillae in the Manchurian chipmunk, Tamias Sibiricus asiaticus. Okajimas folia Ant Jpn. 69 (2-3) :139-43.

Kumar, P.; Kumar, S. and Singh, Y. (1998): Tongue papillae in goat : a scanning electron-microscopic study. Anat. Histol. Embryol. 27(6): 355-7.

Kumar, S. and Bate, L.A. (2004): Scanning electron microscopy of the tongue papillae in the pig (Sus scrofa). Microsc Res Tech 1; 63(5): 235-8. 
Martinez, M.; Martinez, F.; Pinheiro, P.F.; Almedia, C.C.D.; Guida, H.L. and Watanabe, I. (1998): Light and scanning electron microscopic study of the vallate papillae of the opossum (Didelphis albivgentris). Rev. chil. anat.16 (1): 67-73.

Martinez, M.; Martinez, F.; Pinheiro, P.F.; Almedia, C.C.D.; Segatelli, T.M. and Watanabe, I. (2000): Scanning electron microscopic study of the tongue of Chinchila (Chinchila laniger) Rev. Chil. Anat. 18 (1): 53-59.

Martini, F.; Timmons, M. and Mckinley, M. (2000): Human anatomy. Prentice Hall, Upper Saddle River, NJ: 471-2.

Mbiene, J.P.; Maccallum, D.K. and Mistretta, C.M. (1997): Organ cultures of embryonic rat tongue supprt tongue and gustatory papilla morphogenesis in vitro without intact sensory ganglia $\mathrm{J}$ comp Neurol; 377(3) 324-340.

Nair, P. and Schroeder, H. (1981): Variation and density of miroplications in superficial cells of the non oral lining mucosa in the monkey Macacus Fascicularis. Archs Oral Biology 26: 837-43.

Ojima, K.; Saeki, C.; Matsumoto, S. and Takeda, M. (1996): The distributive pattern, form and function seen in microvascular cast specimens of adult rat tongue. Anat Anz,178(6): 531-5.

Okada, S. and Schraufngel, E.D. (2005): Scanning electron microscopic structure of the lingual papillae of the common Opossum (Dideelphis marsupiaqlis). Microsc. Microanal. 11 (4): 319-32.

Pastor, J.F.; Moro, J.A.; Verona, J.A.; Represa, J.J. and Barbosa, E. (1993): Morphological study by scanning electron microscopy of the lingual papillae in the common European bat (Pipistrellus pipistrellus). Arch Oral Biol 38 (7): 597-9.

Paz Cabello, Chamoro C.A.; Sandoval, J. and Fernandez, M. (1988): Comparative scanning electron microscopy study of the lingual papillae in two species of domestic mammals (Equuus caballus and Bos Taurus). Act Anat., 132: 120-23.

Robinson, P.P. (1989): The reinnervation of the tongue and salivary glands after lingual nerve injuries in cat. Brain Res., 483, 259271.

Robinson, P.P. and Winkles, P.A. (1990): Quantitative study of fungiform papillae and taste buds on the cat tongue. Anat. Rec., $225,108-111$. 
Sbarbati, A.; Merigo, F.; Bernardi, P.; Crescimanno, C.; Benati, D. and Osculati, F. (2002): Ganglion cells and topographically related nerves in the vallate papilla/von Ebner gland complex. The Journal of Histochemistry \& Cytochemistry 50(5): 709-718.

Sperry, D.G. and Wassersug, R.J. (1976): A proposed function for microridges on epithelial cells. Anat. Rev.185.253-258.

Utiyama, C.; Watanabe, I.; Koning, B.; Koga, L.; Semprini, M. and Tedesco, $R$. (1995): Scanning electron microscopic study of the dorsal surface of the tongue Callomys callosus mouse. Ann Anat.,177: 569.

Yoshimura, K.; Shindoh, J. and Kobayashi, K. (2002): Scanning electron microscopy study of the tongue and lingual papillae of the California sea lion (Zalophus californianus californianus). Anat. Rec. 267:146-153. 
 